\title{
Needsfinding in Living Labs: A Structured Research Approach
}

Louise Savelkoul and Murk Peutz

\author{
"Cycling is possibly the greatest and most pleasurable form of ") \\ transport ever invented. It's like walking only with one-tenth of \\ the effort. Ride through a city and you can understand its \\ geography in a way that no motorist, contained by one-way signs \\ and traffic jams, will ever be able to. You can whiz from one side \\ to the other in minutes. You can overtake $\$ 250,000$ sports cars \\ that are going nowhere fast. You can park pretty much \\ anywhere. It truly is one of the greatest feelings of freedom one \\ can have in a metropolitan environment. It's amazing you can \\ feel this free in a modern city.
}

\author{
Daniel Pemberton \\ In The Book of Idle Pleasures
}

\begin{abstract}
Living labs enable innovations to be facilitated and implemented quickly and efficiently. A key element of the living lab approach is the active involvement of users. In this article, we examine a structured needsfinding phase of a living lab infrastructure project within the context of bicycle commuting. Given that effectuation costs are high, it is essential for the lab to focus on tackling the right user needs. Thus, the living lab's needsfinding phase aims to identify user needs and wants, as measured by bicycle commuting intention. We examined intention in a structured way by following the theory of planned behaviour. The results show that bicycle commuting intention can be explained by the variables of our model ( $\mathrm{R}$ square $=0.808$ ). The specific insights arising from the needsfinding phase are an important focus for the activities and experiments in the later phases of the living lab. The generalized insights are also relevant to innovation experts outside the area of cycling.
\end{abstract}

\section{Introduction}

Promoting cycling is increasingly considered as a solution for complex mobility problems. However, there is relatively scarce research available about the motivations of bicycle commuters and their needs. Cycling differs from other means of transport and therefore existing large bodies of scientific literature can only be used indirectly (Harms et al., 2014; Wardman et al., 1997). For example, weather and physical effort have more impact on cyclists than on other means of transport. However, a large part of the decision to cycle can be explained by personal factors, allowing the use of more commonly used psychological models (Titze et al., 2008).

This article shares insights from a living lab in the Netherlands that focused on the personal factors influencing bicycle commuting intention. Partners from academia, government, and business wished to identify and un- derstand the needs and requirements of cyclists and potential cyclists. A particular focus was "fast cycling routes", which are routes built to solve the problem of traffic congestion and as an opportunity for organizations to encourage more employees to commute by bike. For this reason, the living lab was called the Living Lab Fast Cycling Routes. A related topic of interest was the availability of electric bicycles (e-bikes), which contribute to this development by expanding the practical commuting range, enabling even more people to consider commuting to work by bicycle.

This article elaborates on the first phase of the living lab: the needsfinding phase. The needsfinding process is developed to "frame" the needs, goals, and values of (prospective) bicycle commuters, their employers, and other stakeholders. This article focuses on the needsfinding phase because it may yield interesting outcomes for the other phases of the living lab and for other living labs in general. 


\section{Needsfinding in Living Labs: A Structured Research Approach}

\section{Louise Savelkoul and Murk Peutz}

The living lab approach has its origins in the experimentation with technology together with users (Niitamo et al., 2006). Whereas it is quite easy to change information quickly and cheaply, this is not the case for infrastructure projects. Furthermore, transport infrastructure projects often do not perform as promised; cost escalations appear to be the rule rather than the exception (Flyvbjerg et al., 2003). The structured focus in the beginning of the living lab is needed because of the high investment costs for this infrastructure project. Outcomes from a freeform living lab method could easily become too expensive to implement in terms of the required infrastructure. By using a structured method, costs are kept to the minimum as the users' wants and needs are measured in a structured way before the roads are being built. Hence, the users' needs and wants are implemented right away and roads do not have to be adjusted at high cost after construction.

The way to integrate this structured approach into the user involvement of the living lab is by a combination of a questionnaire, interviews, and focus group activities. Structuring the needsfinding process in this way makes it easier to respond to the needs of the users in later phases and contributes to a successful living lab. This approach is in line with the lean startup methodology, which suggests that, by validating hypotheses of customer's problems, startups find a solution that indicates there is business potential in solving the problem (Hokkanen et al., 2016). In this living lab, customer's needs and wants are also incorporated before the project/product has its final form.

The needsfinding phase has several steps that follow a logical sequence:

1. Identify technology, incentives, methods, and facilities through survey questionnaires, exploratory interviews, literature reviews, and research at the bicycle highway.

2. Triangulate the data from the questionnaires with other studies.

3. Prioritize the user problems on the basis of effects and costs in later phases.

4. Strengthen selected priorities with interviews and expert sessions.
In this article, we describe how this needsfinding phase was grounded in the theory of planned behaviour to predict bicycle commuting intention in the living lab. In the next section, we outline the theory and show how it was applied to the living lab case. Then, we present our specific methodology and results. Finally, we conclude with a discussion of these results and explore avenues for future research.

\section{The Theory of Planned Behaviour}

The theory of planned behaviour has been widely applied for predicting behavioural intention. In applying this theory, the personal motivational factors of individuals are used as determinants for the likelihood of expressing a specific behaviour (Glanz et al., 2008). Thus, the theory is useful in situations where it is not possible or practical to measure actual behaviour. It has strong predictive power, meaning that behavioural intention predicts actual behaviour (Ajzen, 1991; Armitage \& Conner, 2001; Conner \& Armitage, 1998; Sheppard et al., 1988). Although the theory is often used to predict health-related behaviour and exercise behaviour (Smith et al., 2007), it can be used for other types of behaviour as well.

Behavioural intention can be seen as the willingness of a person to perform a certain behaviour (Fishbein \& Ajzen, 2011). The underlying idea is that behavioural intention encompasses the subjective probability that a person will perform a certain behaviour (Ajzen, 1991). In the current study, the theory of planned behaviour was selected to measure bicycle commuting intention. A positive bicycle commuting intention means that a commuter intends to cycle to work instead of using another means of transport.

The theory of planned behaviour comprises three independent variables that can explain the dependent variable of behavioural intention: i) attitude, ii) subjective norms, and iii) perceived behavioural control. These variables are related to each other in explaining behavioural intention (Fishbein \& Ajzen, 2011), but depending on the case, only one or two variables may be important (Ajzen, 1991). Figure 1 describes the model and shows the relationships between the three variables, which are described in greater detail below, including how they apply to the context of bicycle commuting intention: 


\section{Needsfinding in Living Labs: A Structured Research Approach}

\section{Louise Savelkoul and Murk Peutz}

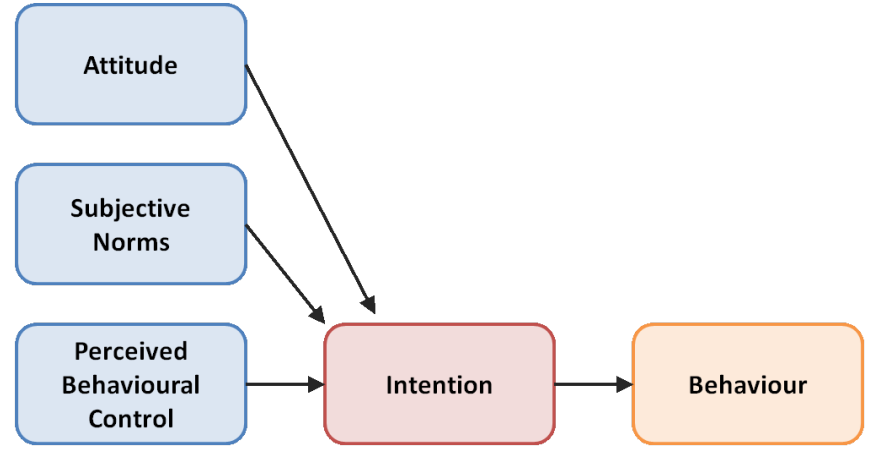

Figure 1. General model underpinning the theory of planned behaviour (Ajzen, 1991)

1. Attitude: this variable encompasses an individual's idea of the consequences of the behaviour and its importance to the individual (Ajzen, 1991; Fishbein \& Ajzen, 2011). In the Netherlands, the attitudes regarding cycling are relatively positive compared to other nations: cycling is part of the Dutch way of living (Harms et al., 2014). A positive cycling attitude increases the likelihood of commuting by bicycle (Dill \& Voros, 2008), and given that cycling levels are so high in the Netherlands, we expect that this positive attitude will lead to a high bicycle commuting intention.

2. Subjective norms: this variable refers to social pressure applied by others (Ajzen, 1991). It differs from attitude in that it focuses on the perception of pressure from the (social) environment instead of the personal perception of the behaviour (Glanz et al., 2008). Within the context of cycling, it is expected that bicycle commuting intention will be determined by an individual's family, friends and colleagues as they create a norm for cycling behaviour (Terry \& Hogg, 1996). For this reason, we expect that high subjective norms will lead to high bicycle commuting intention. Respondents were also asked how important the pressure from family/friends and colleagues was for them.

3. Perceived behavioural control: this variable refers to the belief that a person has control over a specific behaviour (Francis et al., 2004). A difference can be made between internal and external control (Manstead \& Eekelen, 1998), where internal control reflects the skills and capabilities of individuals (e.g., motivation and ability) and external control focuses on the available resources and difficulty of the task (Manstead \& Eekelen, 1998; Terry, 1993). We expect that greater perceived behavioural control will lead to higher behavioural intention.

\section{Added variables to account for contextual factors}

Although the theory of planned behaviour is a valid and often used method for explaining behavioural intention, it only includes personal factors (Glanz et al., 2008). Within the living lab under study here, the user needs and wants are a central element. It is therefore necessary for our model to also include variables relating to the employees' organizational context. In the context of cycling, contextual factors play a large role. For example, Buehler (2012) has demonstrated that bicycle parking, cyclist showers and free car parking are determinants of cycling to work. It seems that the bicycle infrastructure of organizations and the bicycling incentives play a facilitating role in behavioural intention (Chatterjee et al., 2013). Accordingly, we added two variables to the conceptual model, as shown in Figure 2:

4. Facilitating conditions: Perceived facilitating conditions refer to individual beliefs about infrastructures that can remove barriers to the use of a system or can support its use (Venkatesh et al., 2008; Venkatesh et al., 2003). Therefore, it is relevant to consider employees' perceptions of the facilities available at their workplaces rather than simply documenting what facilities are actually available. In particular, we expect that bicycle facilitating conditions will have a positive effect on bicycle commuting intention.

5. Incentive systems: This variable can be described as the variety of incentives that organizations offer to their employees, such as financial incentives for buying or riding a bicycle (e.g., compensation for every kilometre cycled) (Heinen, 2011; Knoke, 1988). The growing interest in financial incentives for promoting cycling reflects findings that incentives are effective, even to the extent that they can almost double cycling levels (Dickinson et al., 2003; Handy \& Xing, 2011; Wardman et al., 1997). For this reason, we expect bicycling-related incentives to have a positive influence on bicycle commuting intention.

\section{Methodology}

Bicycle commuting intention was measured by investigating three organizations in the vicinity of a "fast cycling route" in the Netherlands. The participating organizations were selected on the basis of their location but have different characteristics (public and private) and are from different sectors (healthcare, education, and industry). Employees of these organizations completed a questionnaire by which we measured their bicycle commuting intention. The study had a crosssectional design. Before the actual questionnaire was 


\section{Needsfinding in Living Labs: A Structured Research Approach}

\section{Louise Savelkoul and Murk Peutz}

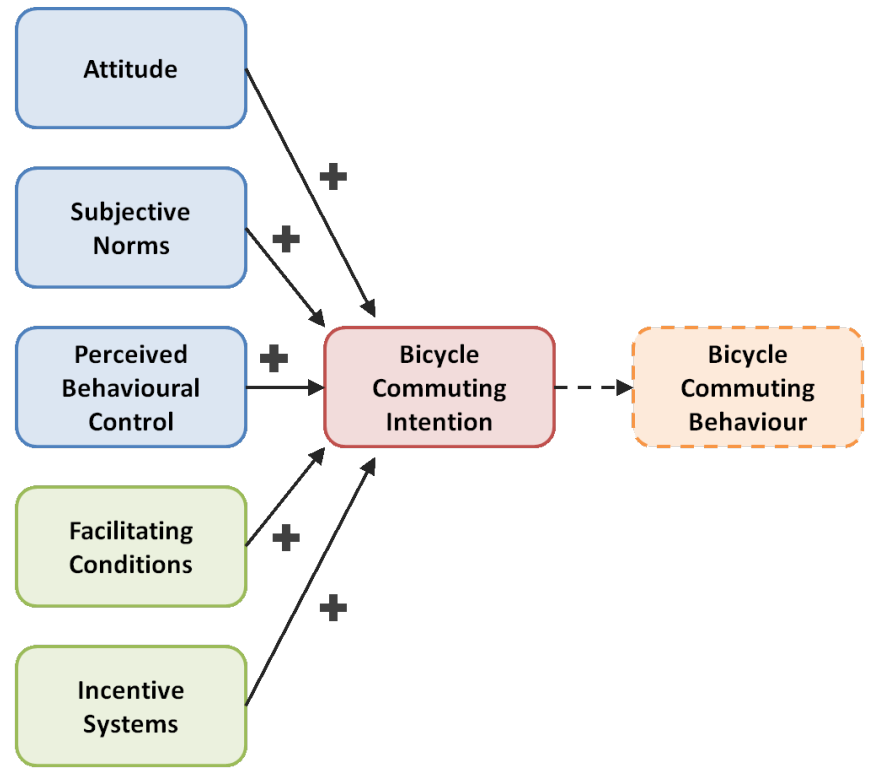

Figure 2. Conceptual model with added variables

sent to the participating organizations, it was sent to a pre-test organization and the feedback was incorporated into the final questionnaire. Only employees who lived within 30 kilometres of their workplace received the questionnaire. This distance was chosen to reflect a maximum commuting distance that would be practical by (electric) bicycle.

The gathering of data was part of the first step in the needsfinding, as described earlier. The bounded population included 3998 employees from the organizations under study. It was not necessary to do further sampling because everyone within the distance of 30 kilometres could fill in the questionnaire (convenience sampling). The questionnaire was based on literature sources measuring the variables of the theory of planned behaviour and the contextual variables and from questionnaires designed to evaluate bicycle commuting. A unipolar scale with five response categories was used because it has been shown to be valid for measuring behavioural intention (Thomas et al., 2004).

\section{Data measurement and analysis}

To measure bicycle commuting intention, multiple questions should be included (Ajzen, 2002). We included questions that followed Gibbons' (2005) splitting of behavioural intention into subdimensions to better predict actual behaviour: implementation intentions (planning behaviour), behavioural expectations (predicting behaviour), and behavioural willingness (openness to risk).
Attitude was measured according to the sub-items "direct benefit", "awareness", and "safety". To ensure validity, confirmatory principal component analysis (PCA) was performed on the nine items of attitude. The pattern matrix showed that the component "safety" was part of the component "direct benefit" and was therefore subsequently combined within it. This led to the following distribution of items: i) direct benefit including comfortability, lifestyle, pleasant/nice, time saving, and safety and ii) awareness including health benefits, cost saving, environmental benefits, and pleasantness.

Subjective norms were measured separately by normative beliefs and importance. PCA showed that the components differed from Heinen (2011). But, because the measurement of Heinen (2011) had a clear distribution (colleagues, family and friends), her distribution was used.

Perceived behavioural control was measured by two internal control items (confidence and trust) and one external control variable (constraint).

Facilitating conditions included questions about bicycle facilities and other facilities. The participating organizations' incentive systems were measured by financial incentives; other incentives were excluded due to insufficient correlation.

The following control variables were taken into account: gender, age, working hours, physical condition, car ownership, household structure, distance to work, luggage, frequency of past behaviour, and organization. Dummy variables were made for the control variables household structure (household structure 3 is the reference category), time block (multiple answers possible), and organization (company A is the reference category).

Missing values and outliers were checked and negatively formulated items were reversed. Thereafter, PCA was performed along with descriptive statistical analyses. Next, multiple hierarchical regression analyses were performed (see Appendix 1). For reasons of brevity, the control variables are presented only once without independent variables (model 1). First, the variables associated with the theory of planned behaviour were measured in total (model 2). Thereafter, the variables were separately measured (models 3, 4, and 5). Then, the contextual variables were measured (models 6 and 7). Model 8 includes all the independent variables. The additional multiple regressions for the three variables are included in models 9, 10, and 11. 


\section{Needsfinding in Living Labs: A Structured Research Approach}

\section{Louise Savelkoul and Murk Peutz}

\section{Results}

\section{Multiple regression and hypothesis testing}

We received 647 successfully completed questionnaires, which corresponds to a $16 \%$ response rate. Missing values were excluded pairwise. There were no striking outliers. Checks were carried out to ensure a sample size large enough for multicollinearity and singularity, distribution normality, linearity, homoscedasticity, and outliers. All the assumptions were met. Only the Mahalonobis distance was exceeded when outliers were checked. However, because the Cook distance was less than 1, there was no need to delete cases. Therefore, multiple regressions were appropriate.

The model including all the variables had an $\mathrm{R}$ square of 0.808 which is extremely high for testing the model of the theory of planned behaviour. Even without the contextual variables, the R square was still 0.807 . Meta-analyses have shown that the explaining variance of behavioural intention by use of the theory of planned behaviour normally lies between $40 \%$ and $50 \%$ (Sutton, 1998). The high explaining variance means that this theory is a valid way to measure bicycle commuting intention.

The standardized coefficients were used to compare the contributing variables of bicycle commuting intention.

\section{Variables}

Appendix 1 shows the findings of the multiple regression analyses, which are summarized in Table 1 .
Attitude had a statistically significant impact on bicycle commuting intention $F$ Change $(2.567)=49.203$, p $<.001$. The dimensions of attitude were also tested. The dimension "awareness" did not have a significant effect on bicycle commuting intention, whereas the dimension "direct benefit" had a significant beta value $(0.298$, $\mathrm{p}<0.001)$.

The findings show that, for the variable subjective norms, only family had a significant contribution to bicycle commuting intention (bfamily $=0.231, \mathrm{p}<0.001$ ). Importance of subjective norms did not have a significant contribution to bicycle commuting intention.

Perceived behavioural control had a significant impact on bicycle commuting intention. The contribution of perceived behavioural control is large in comparison to the other two variables.

For facilitating conditions, the $\mathrm{R}$ square changes from 0.713 to 0.714 (see model 6) but the change is not significant $F$ change (2.595) $=0.683$, p $>0.05)$.

Concerning incentive systems, only financial incentives of the organization were incorporated in the multiple regression. Financial incentives explained an additional two percent of variance in bicycle commuting intention but not a significant level $F$ change (1.596) $=3.240$, $\mathrm{p}>0.05$ ).

The control variable past behaviour had a significant influence on bicycle commuting intention in all models.

Table 1. Observed effects of variables and sub-items on bicycle commuting intention

\begin{tabular}{llll}
\hline Variable & Observed Effect & Significance & Conclusion \\
\hline Attitude & Positive & $\begin{array}{l}\text { Direct benefit significant, } \\
\text { awareness not significant }\end{array}$ & Partially confirmed \\
\hline Subjective norms & Positive & $\begin{array}{l}\text { Subjective norms significant, } \\
\text { importance not significant }\end{array}$ & Partially confirmed \\
\hline Perceived behavioural control & Positive & Significant & Confirmed \\
\hline Facilitating conditions & Negative & Not significant & Rejected \\
\hline Incentive systems & Positive & Not Significant & Rejected \\
\hline Past behaviour & Positive & Significant & Control variable \\
\hline
\end{tabular}




\section{Needsfinding in Living Labs: A Structured Research Approach}

\section{Louise Savelkoul and Murk Peutz}

\section{Discussion and Conclusion}

The ultimate goal of the living lab "Fast Cycling Routes" is to encourage cycling among employees of organizations in close proximity of fast cycling routes. This goal is aligned with the intention of the Dutch government's to build 675 kilometres of fast cycling routes by 2025 . But, enabling new physical infrastructure to be built will by itself not lead to more cycling. The intention to use it must be understood and addressed.

This research demonstrates that applying a structured approach as part of the needsfinding phase is promising. This research confirms by its high explaining variance that the model derived from the theory of planned behaviour is a valid way to research behavioural intention ( $\mathrm{R}$ square $=0.808$ ). The study builds upon earlier work regarding bicycle commuting intention and extends it with a combination of personal and contextual factors. Earlier work concentrated on either personal factors or contextual factors. Therefore, a more comprehensive overview of bicycle commuting intention is achieved by combining these factors into one study. One explanation for why the results for facilitating conditions and financial bicycle incentives (the contextual variables) were not significant could be because perceived conditions were measured instead of actual facilities and incentives. Future applied research could elaborate further on these results to understand if this explanation is appropriate.

Furthermore, this research shows that for the development of fast cycling routes, a personal or psychographic factor should be included (e.g., perceived behavioural control, subjective norms of the family, or the attitude dimension direct benefit). This means that the intrinsic drivers of bicycle commuting intention should receive more attention because they explain a large part of the intention to commute by bicycle. This is especially valid when the variables are split up into sub-items.

This finding led to input for the following steps in the needsfinding phase. The interviews with stakeholders were more focused on psychographic elements than would have been the case without the findings of this study. Also, the focus sessions with experts addressed the behavioural side of cycling. Without these results, the behavioural side would not have been discussed. In this way, it helped the researchers to avoid the themes for which the effect on behaviour were not significant but provided living lab actors with proven themes for brainstorming in the needsfinding phase.
Moreover, by mapping the needs of the end users, a better plan can be made for the later phases in the living lab. The researchers now know that prototypes of innovations have to include behavioural components. For example, knowing that the family plays an important role in the bicycle commuting intention, researchers can ensure that they involve families in the research. These findings give the opportunity to test this effect in a later phase (after the needsfinding phase). For example, by including families of employees in an experiment, the lab can assess how the family can stimulate a family member to commute to work by bicycle.

Another measurement in the test phase may consist of promotion campaigns that are focused on direct benefit, as this seemed to have a significant influence on bicycle commuting intention. Often in the Netherlands, promotion campaigns about cycling are focused on safety. However, this research shows that the items of direct benefit have to be emphasized in order to stimulate bicycle commuting intention. These items concern: the comfortability of the route, the pleasure derived from riding a route, and how easy it can be to fit cycling into most lifestyles. Given that these elements have a significant influence on bicycle commuting intention for potential cyclists, communication geared towards these elements would lead to a higher bicycle commuting intention. However, in the Netherlands, home and work are not fully integrated. Therefore, results from country to country may differ and promotion campaigns should be designed accordingly. For this living lab in the Netherlands, emphasis will be placed on providing more direct benefit in campaigns.

Furthermore, this research has also clarified what type of people (users) should be selected for the subsequent phase in the living lab. On the one hand, the control variable past behaviour had a direct effect on bicycle commuting intention and can therefore be seen as an additional independent variable. It is therefore important for employers to give their employees a good experience when they cycle to work for the first time, because the intention to cycle more often is directly dependent on (positive) past behaviour. On the other hand, the variable with the largest effect on bicycle commuting intention is perceived behavioural control. This variable had an interaction effect with working distance. The influence of working distance decreases if employees are provided with more control in cycling to work. 


\section{Needsfinding in Living Labs: A Structured Research Approach}

\section{Louise Savelkoul and Murk Peutz}

Both findings can be tested in a new phase of the living lab. One way to test this is by introducing employees to an electric bicycle and test whether their perceived behavioural control changes over time. Also, introducing the electric bicycle to (new) employees would make commuting easier (past behaviour). Alternatively, by using an electric bicycle, the time of arrival at work becomes more predictable as compared to public transport, which also contributes to perceived behavioural control.

All in all, this research provides insights in how to tackle the next phases in the living lab. The findings give guidance in an unstructured process of user requirements and needs. Accordingly, topics are being discussed in conversations with users that would not have been discussed without these findings. The findings show that changes should be made in the regular approach of cycle programs offered by governmental institutions and employers to encourage employees to cycle to work. Not only contextual factors are making a difference in the intention to cycle to work. In fact, this research shows that personal factors are particularly important. For this reason, organizations should reevaluate their strong focus on contextual interventions and put more focus on personal factors in their bicycle policy programs and living labs. Future researchers should keep an eye on the process of a living lab, and provide a structure to measure the stakeholders' findings, for example by dividing the living lab into phases.

\section{References}

Ajzen, I. 1991. The Theory of Planned Behavior. Organizational Behavior and Human Decision Processes, 50: 179-211. http://dx.doi.org/10.1016/0749-5978(91)90020-T

Ajzen, I. 2002. Constructing a TpB Questionnaire: Conceptual and Methodological Considerations. Amherst, MA: University of Massachusetts.

Armitage, C. J., \& Conner, M. 2001. Efficacy of the Theory of Planned Behaviour: A Meta-Analytic Review. British Journal of Social Psychology, 40(4): 471-499.

http://dx.doi.org/10.1348/014466601164939

Buehler, R. 2012. Determinants of Bicycle Commuting in the Washington, DC Region: The Role of Bicycle Parking, Cyclist Showers, and Free Car Parking at Work. Transportation Research Part D: Transport and Environment, 17(7): 525-531. http://dx.doi.org/10.1016/j.trd.2012.06.003

Chatterjee, K., Sherwin, H., \& Jain, J. 2013. Triggers for Changes in Cycling: The Role of Life Events and Modifications to the External Environment. Journal of Transport Geography, 30: 183-193. http://dx.doi.org/10.1016/j.jtrangeo.2013.02.007

\section{About the Authors}

Louise Savelkoul is a Consultant at Equator Research and is a $\mathrm{PhD}$ candidate studying user innovation at Tilburg University in the Netherlands, where she also holds Bachelor and MSc degrees in Organizational Studies. At Equator Research, her focus is on Living Labs. She is currently Lab Manager of the regional cycle lanes initiative in the Netherlands, enabling new innovations in infrastructure and the built environment. Recently she co-developed the flexible living for health care lab in the Southern Netherlands.

Murk Peutz is Director of Equator Research, a consulting firm focused on innovation management and the use of living labs as an effective tool for cocreation and collaborative innovation. He graduated from Delft University with a degree in Mechanical Engineering, and he holds a Business Law degree from Leiden University and an MBA from INSEAD. He has also worked in industry (Tate \& Lyle PLC) and management consulting (The Boston Consulting Group). In 2004, he took up responsibility for Innovation Consulting to Small and Medium Enterprises as Director of the Syntens Foundation before founding Equator Research in 2013. Murk is also a non-executive director of several companies in the Netherlands.
Conner, M., \& Armitage, C. J. 1998. Extending the Theory of Planned Behavior: A Review and Avenues for Further Research. Journal of Applied Social Psychology, 28(15): 1429-1464.

http://dx.doi.org/10.1111/j.1559-1816.1998.tb01685.x

Dickinson, J. E., Kingham, S., Copsey, S., \& Pearlman Hougie, D. J. 2003. Employer Travel Plans, Cycling and Gender: Will Travel Plan Measures Improve the Outlook for Cycling to Work in the UK? Transportation Research Part D: Transport and Environment, 8(1): 53-67.

http://dx.doi.org/10.1016/S1361-9209(02)00018-4

Dill, J., \& Voros, K. 2008. Factors Affecting Bicycling Demand: Initial Survey Findings from the Portland, Oregon, Region. Transportation Research Record, 2031(1): 9-17. http://dx.doi.org/10.3141/2031-02

Fishbein, M., \& Ajzen, I. 2011. Predicting and Changing Behavior: The Reasoned Action Approach. New York: Taylor \& Francis.

Flyvbjerg, B., Skamris holm, M. K., \& Buhl, S. L. 2003. How Common and How Large Are Cost Overruns in Transport Infrastructure Projects? Transport Reviews, 23(1): 71-88. http://dx.doi.org/10.1080/01441640309904 


\section{Needsfinding in Living Labs: A Structured Research Approach}

\section{Louise Savelkoul and Murk Peutz}

Francis, J., Eccles, M. P., Johnston, M., Walker, A. E., Grimshaw, J. M., Foy, R., Kaner, E. F. S., Smith, L., \& Bonetti, D. 2004. Constructing Questionnaires Based on the Theory of Planned Behaviour: A Manual for Health Services Researchers. Newcastle upon Tyne: University of Newcastle.

Gibbons. F. X. 2005. Behavioral Intentions, Expectations and Willingness. Bethesda, MD: National Cancer Institute, Division of Cancer Control \& Population Sciences. http://cancercontrol.cancer.gov/brp/research/constructs/intentexpect-willingness.html

Glanz, K., Rimer, B. K., \& Viswanath, K. (Eds.). 2008. Health Behavior and Health Education: Theory, Research, and Practice. San Francisco, CA: Jossey-Bass

Handy, S. L., \& Xing, Y. 2011. Factors Correlated with Bicycle Commuting: A Study in Six Small U.S. Cities. International Journal of Sustainable Transportation, 5(2): 91-110. http://dx.doi.org/10.1080/15568310903514789

Harms, L., Bertolini, L., \& te Brömmelstroet, M. 2014. Spatial and Social Variations in Cycling Patterns in a Mature Cycling Country Exploring Differences and Trends. Journal of Transport and Health, 1(4): 232-242.

http://dx.doi.org/10.1016/j.jth.2014.09.012

Heinen, E. 2011. Bicycle Commuting. Delft, Netherlands: Delft University Press.

Hokkanen, L., Kuusinen, K., \& Väänänen, K. 2016. Minimum Viable User EXperience: A Framework for Supporting Product Design in Startups. In H. Sharp \& T. Hall (Eds.), Agile Processes, in Software Engineering, and Extreme Programming. XP 2016. Lecture Notes in Business Information Processing, 251: 66-78. Cham, Switzerland: Springer.

http://dx.doi.org/10.1007/978-3-319-33515-5_6

Knoke, D. 1988. Incentives in Collective Action Organizations. American Sociological Review, 53(3): 311-329.

http://www.jstor.org/stable/2095641

Manstead, A. S. R., \& Eekelen, S. A. M. 1998. Distinguishing Between Perceived Behavioral Control and Self-Efficacy in the Domain of Academic Achievement Intentions and Behaviors. Journal of Applied Social Psychology, 28(15): 1375-1392. http://dx.doi.org/10.1111/j.1559-1816.1998.tb01682.x

Niitamo, V.-P., Kulkki, S., Eriksson, M., \& Hribernik, K. A. 2006 Stateofthe-Art and Good Practice in the Field of Living Labs. In K. S. Thoben, Pawar, M. Taisch, \& S. Terzi (Eds.). Proceedings of the 12th International Conference on Concurrent Enterprising: Innovative Products and Services through Collaborative Networks:349-357.
Smith, J. R., Terry, D. J., Manstead, A. S. R., Louis, W. R., Kotterman, D., \& Wolfs, J. 2007. Interaction Effects in the Theory of Planned Behavior: The Interplay of Self-Identity and Past Behavior. Journal of Applied Social Psychology, 37(11): 2726-2750. http://dx.doi.org/10.1111/j.1559-1816.2007.00278.x

Sutton, S. 1998. Predicting and Explaining Intentions and Behavior: How Well Are We Doing? Journal of Applied Social Psychology, 28(15): 1317-1338. http://dx.doi.org/10.1111/j.1559-1816.1998.tb01679.x

Terry, D. J. 1993. Self-Efficacy Expectations and the Theory of Reasoned Action. International Series in Experimental Social Psychology, 28(2): 135-151. http://dx.doi.org/10.1207/s15326985ep2802_3

Terry, D. J., \& Hogg, M. A. 1996. Group Norms and the AttitudeBehavior Relationship: A Role for Grop Identification. Personality and Social Psychology Bulletin, 22(8): 776-793. http://psycnet.apa.org/doi/10.1177/0146167296228002

Thomas, R. K., Terhanian, G., \& Bayer, L. R. 2004. Behavioral Intention Measurement: International Findings. In Proceedings of International Sociology Association's 6th International Conference on Social Science Methodology: 16-20. Amsterdam, Netherlands: International Sociology Association.

Titze, S., Stronegger, W. J., Janschitz, S., \& Oja, P. 2008. Association of Built-Environment, social-Environment and Personal Factors with Bicycling as a Mode of Transportation among Austrian City Dwellers. Preventive Medicine, 47(3): 252-259. http://dx.doi.org/10.1016/j.ypmed.2008.02.019

Venkatesh, V., Brown, S. A., Maruping, L. M., \& Bala, H. 2008. Predicting Different Conceptualizations of System Use: The Competing Roles of Behavioral Intention, Facilitating Conditions, and Behavioral Expectation. MIS Quarterly, 32(3): 483-502. http://www.jstor.org/stable/25148853

Venkatesh, V., Morris, M. G., Davis, G. B., \& Davis, F. D. 2003. User Acceptance of Information Technology: Toward a Unified View. MIS Quarterly, 27(3): 425-478. http://www.jstor.org/stable/30036540

Wardman, M., Hatfield, R., \& Page, M. 1997. The UK National Cycling Strategy: Can Improved Facilities Meet the Targets? Transport Policy, 4(2): 123-133. http://dx.doi.org/10.1016/S0967-070X(97)00011-5 


\section{Needsfinding in Living Labs: A Structured Research Approach}

\section{Louise Savelkoul and Murk Peutz}

\section{Appendix 1. Multiple regression analyses}

\section{A. Main analyses}

\begin{tabular}{|c|c|c|c|c|c|c|c|c|}
\hline Step 1: Control Variables & 1 & 2 & 3 & 4 & 5 & 6 & 7 & 8 \\
\hline Gender & -0.006 & -0.023 & -0.024 & -0.005 & -0.015 & -0.008 & -0.004 & -0.025 \\
\hline Age & -0.009 & -0.036 & -0.034 & -0.002 & -0.034 & -0.008 & -0.008 & -0.037 \\
\hline Working distance & $-0.136^{* * *}$ & -0.014 & $-0.117^{* * *}$ & $-0.094^{* * *}$ & -0.018 & $-0.135^{* * *}$ & $-0.135^{* * *}$ & -0.012 \\
\hline Household structure $1^{\dagger}$ & -0.040 & -0.016 & -0.030 & -0.030 & -0.025 & -0.040 & -0.041 & -0.017 \\
\hline${\text { Household structure } 2^{\dagger}}^{+}$ & 0.019 & 0.035 & 0.019 & 0.037 & 0.027 & 0.020 & 0.018 & 0.032 \\
\hline Household structure $4^{\dagger}$ & -0.006 & -0.001 & -0.011 & -0.017 & 0.012 & -0.002 & -0.006 & 0.001 \\
\hline Household structure $5^{\dagger}$ & -0.008 & 0.003 & -0.009 & -0.005 & 0.005 & -0.008 & -0.007 & 0.004 \\
\hline 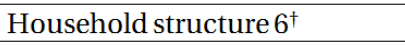 & -0.015 & -0.016 & -0.017 & -0.009 & -0.020 & -0.015 & -0.014 & -0.015 \\
\hline Household structure $7^{\dagger}$ & 0.025 & 0.033 & 0.019 & 0.034 & 0.033 & 0.026 & 0.024 & 0.031 \\
\hline Working hours & -0.030 & -0.017 & -0.001 & -0.030 & -0.034 & -0.030 & -0.030 & -0.016 \\
\hline Timeblock1 $(06.00 \mathrm{u}-12.00 \mathrm{u})$ & -0.041 & -0.035 & -0.035 & -0.039 & -0.039 & -0.039 & -0.044 & -0.037 \\
\hline Timeblock2 (12.00u-18.00u) & 0.064 & 0.038 & 0.046 & 0.032 & $0.065^{*}$ & 0.062 & 0.061 & 0.038 \\
\hline Timeblock3 $(18.00 \mathrm{u}-24.00 \mathrm{u})$ & 0.005 & 0.029 & 0.021 & 0.015 & 0.018 & 0.007 & 0.006 & 0.030 \\
\hline Timeblock4 $(00.00 \mathrm{u}-06.00 \mathrm{u})$ & -0.047 & -0.011 & -0.039 & -0.037 & -0.015 & -0.047 & -0.045 & -0.010 \\
\hline Timeblock5 (no usual time) & 0.022 & 0.013 & 0.019 & 0.016 & 0.016 & 0.024 & 0.019 & 0.015 \\
\hline Luggage & -0.006 & 0.010 & -0.002 & -0.008 & 0.015 & -0.004 & -0.006 & 0.010 \\
\hline Frequency of past behaviour & $0.750^{* * *}$ & $0.355^{* * *}$ & $0.566^{* * *}$ & $0.631^{* * *}$ & $0.452^{* * *}$ & $0.750^{* * *}$ & $0.743^{* * *}$ & $0.352^{* * *}$ \\
\hline Physical condition & $0.053^{*}$ & 0.005 & 0.007 & $0.044^{*}$ & 0.031 & $0.053^{*}$ & $0.055^{*}$ & 0.006 \\
\hline Car ownership & 0.005 & 0.037 & 0.041 & 0.008 & 0.019 & 0.006 & 0.006 & 0.041 \\
\hline Organization $2 \ddagger$ & 0.047 & 0.036 & 0.043 & $0.047^{*}$ & 0.035 & 0.039 & $0.058^{*}$ & 0.035 \\
\hline Organization $3 \ddagger$ & 0.037 & -0.009 & 0.005 & 0.036 & 0.000 & 0.022 & 0.053 & -0.022 \\
\hline Step 2: Main Effects & 1 & 2 & 3 & 4 & 5 & 6 & 7 & 8 \\
\hline Attitude: direct benefit & & $0.179^{* * *}$ & $0.298^{* * *}$ & & & & & $0.179^{* * *}$ \\
\hline Attitude: awareness & & 0.005 & 0.015 & & & & & 0.004 \\
\hline Subjective norms: colleagues & & 0.052 & & 0.056 & & & & 0.051 \\
\hline Subjective norms: family & & $0.116^{* *}$ & & $0.231^{* * *}$ & & & & $0.111^{* *}$ \\
\hline Subjective norms: friends & & -0.049 & & -0.054 & & & & -0.046 \\
\hline Subjective norm importance & & 0.012 & & 0.015 & & & & 0.011 \\
\hline Perceived behavioural control & & $0.355^{* * *}$ & & & $0.470^{* * *}$ & & & $0.360^{* * *}$ \\
\hline Facilities bike & & & & & & -0.025 & & -0.033 \\
\hline Facilities other & & & & & & 0.021 & & -0.005 \\
\hline Financial incentives bike & & & & & & & 0.044 & 0.021 \\
\hline $\mathrm{R} 2$ & 0.713 & 0.807 & 0.756 & 0.748 & 0.780 & 0.714 & 0.715 & 0.808 \\
\hline Adj. R2 & 0.703 & 0.797 & 0.746 & 0.737 & 0.772 & 0.703 & 0.704 & 0.797 \\
\hline F change & $70.774^{* * *}$ & $38.401^{* * *}$ & $49.203^{* * *}$ & $19.917^{* * *}$ & $175.785^{* * *}$ & 0.683 & 3.24 & $27.199^{* * *}$ \\
\hline $\mathrm{F}$ & $70.774^{* * *}$ & $83.025^{* * *}$ & $76.303^{* * *}$ & $69.177^{* * *}$ & $93.516^{* * *}$ & $64.611^{* * *}$ & $67.958^{* * *}$ & $75.108^{* * *}$ \\
\hline part correlation & & & 0.179 & 0.134 & 0.258 & & & \\
\hline
\end{tabular}

$\mathrm{N}=$ between 595 and 647

$* \mathrm{p}<0.05 ; * * \mathrm{p}<0.01 ; * * * \mathrm{p}<0.001$

$\dagger$ Household structure 3 is the reference category

$\uparrow$ Organization 1 is the reference category 


\section{Needsfinding in Living Labs: A Structured Research Approach}

Louise Savelkoul and Murk Peutz

\section{Appendix 1. Multiple regression analyses (continued)}

\section{B. Additional analyses}

\begin{tabular}{|c|c|c|c|}
\hline Step 1: Control Variables & 9 & 10 & 11 \\
\hline Gender & -0.029 & -0.004 & -0.016 \\
\hline Age & -0.043 & -0.007 & -0.035 \\
\hline Working distance & $-0.148^{* * *}$ & $-0.095^{* *}$ & 0.003 \\
\hline Household structure $1^{\dagger}$ & -0.019 & -0.031 & -0.026 \\
\hline 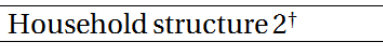 & 0.016 & 0.032 & 0.025 \\
\hline Household structure $4^{\dagger}$ & -0.017 & -0.020 & 0.000 \\
\hline${\text { Household structure } 5^{\dagger}}^{\dagger}$ & -0.009 & -0.005 & -0.007 \\
\hline${\text { Household structure } 6^{\dagger}}^{+}$ & -0.014 & -0.011 & -0.025 \\
\hline Household structure $7^{\dagger}$ & 0.017 & 0.035 & 0.036 \\
\hline Working hours & -0.005 & -0.034 & $-0.038^{*}$ \\
\hline Timeblock1 (06.00u-12.00u) & -0.023 & -0.037 & -0.015 \\
\hline Timeblock2 (12.00u-18.00u) & 0.044 & 0.032 & 0.043 \\
\hline Timeblock3 (18.00u-24.00u) & 0.017 & 0.011 & 0.009 \\
\hline Timeblock4 (00.00u-06.00u) & -0.038 & -0.033 & -0.027 \\
\hline Timeblock5 (no usual time) & 0.014 & 0.016 & 0.019 \\
\hline Luggage & 0.003 & -0.009 & 0.009 \\
\hline Frequency of past behaviour & $0.533^{* * *}$ & $0.632^{* * *}$ & $0.386^{* * *}$ \\
\hline Physical condition & -0.008 & $0.044^{*}$ & 0.036 \\
\hline Car ownership & 0.029 & 0.006 & 0.033 \\
\hline Organization $2 \ddagger$ & 0.039 & $0.051^{*}$ & 0.031 \\
\hline Organization $3 \ddagger$ & -0.012 & 0.039 & -0.001 \\
\hline Step 2: Main Effects & 9 & 10 & 11 \\
\hline Attitude lifestyle & $0.136^{* * *}$ & & \\
\hline Attitude time saving & 0.042 & & \\
\hline Attitude comfortable & $0.082^{*}$ & & \\
\hline Attitude pleasantness & $0.139^{* * *}$ & & \\
\hline Subj.n. colleague: expect & & 0.053 & \\
\hline Subj.n. colleague: encourage & & -0.006 & \\
\hline Subj.n. colleague: appreciate & & 0.028 & \\
\hline Subj.n. family: expect & & $0.129 * *$ & \\
\hline Subj.n. family: encourage & & 0.061 & \\
\hline Subj.n. family: appreciate & & $0.082^{*}$ & \\
\hline Subj.n. friends: expect & & $-0.125^{* *}$ & \\
\hline Subj.n. friends: encourage & & 0.058 & \\
\hline Subj.n. friends: appreciate & & 0.002 & \\
\hline PBC opportunity & & & $0.124^{* * *}$ \\
\hline PBC trust & & & $0.472^{* * *}$ \\
\hline PBC reversed hampered & & & 0.009 \\
\hline $\mathrm{R} 2$ & 0.771 & 0.752 & 0.819 \\
\hline Adj. R2 & 0.761 & 0.739 & 0.812 \\
\hline F change & $36.421^{* * *}$ & $9.967^{* * *}$ & $113.749 * * *$ \\
\hline $\mathrm{F}$ & $78.491^{* * *}$ & $58.565^{* * *}$ & $110.196 * * *$ \\
\hline
\end{tabular}

$\mathrm{N}=$ between 595 and 647

$* \mathrm{p}<0.05 ; * * \mathrm{p}<0.01 ; * * * \mathrm{p}<0.001$

$\uparrow$ Household structure 3 is the reference category

$\downarrow$ Organization 1 is the reference category 